\title{
A Simple Model for Simulating Infiltration in Two- Layer Soil Slope during Unsteady Rainfall and its Application in Slope Stability Analysis
}

Shaohong Li ( $\square$ lishaohong16@126.com)

Southwest Jiaotong University

\section{Shixin Zhang}

Chongqing Three Gorges University

Guoguo Liu

Southwest Jiaotong University

Shuairun Zhu

Chengdu University of Technology

\section{Research Article}

Keywords: infiltration, unsteady rainfall, two-layer soil slope, slope stability

Posted Date: July 8th, 2021

DOl: https://doi.org/10.21203/rs.3.rs-670897/v1

License: (c) (i) This work is licensed under a Creative Commons Attribution 4.0 International License. Read Full License 
5

\title{
A simple model for simulating infiltration in two-layer soil slope during unsteady rainfall and its application in slope stability analysis
}

\author{
S. H. Lia)* S. X. Zhang ${ }^{\text {b) }}$, G.G. Liu ${ }^{\left.\mathrm{c}^{*}\right)}$, S. R. Zhu ${ }^{\mathrm{d})}$
}

a) Department of Geological Engineering, Southwest Jiaotong University, Chengdu 610031,

China

b) School of Civil Engineering, Chongqing Three Gorges University, Wanzhou 404100, China

c) Key Laboratory of Transportation Tunnel Engineering of Ministry of Education, Southwest

Jiaotong University, Chengdu 610031, China

d) College of Environment and Civil Engineering, Chengdu University of Technology,

Chengdu 610059, China

*Corresponding author Email:

lishaohong16@126.com (S. H. Li); 1damienrice@my.swjtu.edu.cn (G.G. Liu);

Submitted on June 29, 2021 
Abstract

Based on the Darcy's law and water balance principle, some infiltration models have been proposed, but most of these models are not suitable for simulating infiltration into layered soils

during unsteady rainfall. In this paper, a simple model for simulating water infiltration into the two-layer soil slopes during unsteady rainfall was proposed, combined with the limit equilibrium method to analyze the stability of the two-layer soil slope. The water infiltration rate of slopes depends on rainfall intensity and the actual infiltration capacity of soils. The proposed model has been successfully applied to three cases (steady rainfall and homogeneous slope, unsteady rainfall and homogeneous slope, unsteady rainfall and two-layer soil slope), and it can be also combined with probabilistic methods to calculate the failure probability of slopes. Compared with the Richards model, the combination of the proposed model and the random field method can quickly obtain the failure probability of the slope.

Keywords: infiltration; unsteady rainfall; two-layer soil slope; slope stability 


\section{Introduction}

Water infiltration in soils is an important issue in Geological Engineering and Soil Science (Collins and Znidarcic 2004; Tang et al. 2015). The Green-Ampt model, proposed by Green and Ampt (1911), is a fundamental mathematical model to describe the infiltration process. Due to its simplicity, it has received widespread attention. A modified model reflecting the relationship between rainfall intensity and infiltration capacity was proposed by Mein and Larsen (1973). Barry et al. (2005) gave some approximate solutions of Green-Ampt model, which are useful for engineering applications. Based on the numerical solutions of Richards equation, an improved Green-Ampt model that can take into account the effect of groundwater levels was developed by Liu (2013). Considering the relationship between rainfall intensity and infiltration capacity, an explicit solution to Green-Ampt model was developed by Almedeij and Esen (2014). The application range of Green-Ampt model was extended from homogeneous to layered soils by Deng and Zhu (2016). An improved Green-Ampt model considering capillary pressure was proposed by Zhang et al. (2019). Considering the piston assumption of GreenAmpt model simplifies the moisture distribution and overestimates the value, Mao et al. (2016) proposed a method to modify the Green-Ampt model by the amount of soil infiltration. The above (i.e., Mein and Larsen's model, Liu's model, Almedeij and Esen's model, Deng and Zhu's model, Zhang's model, and Mao's model) are modified Green-Ampt models based on physical concepts. Different from these studies, a fractional form of the Green-Ampt model, which introduced a new operation rule, was written by Voller (2011). This approach was cited by Fernández-Pato et al. (2018).

However, most of the published studies focus on the infiltration in horizontal soils, 
increasing attention has been paid from geotechnical engineers to the infiltration in soil slopes, which affects the slope stability and then induces geological disasters (Tsaparas et al. 2002; Liu et al. 2014; Zhang et al. 2017). Green-Ampt model has been gradually applied to slope infiltration during rainfall. For example, a Green-Ampt model for slopes was proposed based on coordinate transformation (Chen and Young 2006); The Green-Ampt model and infinite slope model were used to evaluate the stability of landslides in Italy (Muntohar and Liao 2010); A laboratory test was used to evaluate the accuracy of a new Green-Ampt model, and then a landslide stability assessment method based on the new model and the infinite slope model was also developed (Wu et al. 2018); A novel Green-Ampt model considering the effect of slope length was proposed (Wang et al. 2017).

Although the above models have certain applicability, they are not suitable for simulating the infiltration into layered soils during unsteady rainfall. However, rainfall is not uniform and most of slopes are inhomogeneous on the earth (Alcantara-Ayala 2004; Dai et al. 2002). The schematic diagram of rainfall infiltration into a two-layer slope is shown in Fig.1. Due to the unsteady of rainfall and the differences of soil physical and mechanical parameters in different layers, it is difficult to study the infiltration behavior of water in the two-layer soil slope. Some methods for analyzing the infiltration in two-layer soil slopes have been developed. For example, Zhan et al. (2013) obtained an analytical solution of Richards' equation for describing rainfall infiltration by Laplace transform; De Luca and Cepeda (2016) developed a simple program to solve the Richards' equation for a two-layer soil slope; Wu et al. (2020) obtained an analytical solution of infiltration of two-layer soil slope considering hydraulic coupling; Zhu et al. (2020) proposed an improved Chebyshev semi-iterative method to analyze the infiltration 
process of water in the two-layer slope. Unfortunately, these methods were obtained by solving the Richards equation. Although they are more completed in theory, its application in actual engineering is limited due to the complicated mathematical expression and they are only used in the case of uniform rainfall. Cho (2009) proposed a method for analyzing two-layer slope infiltration during steady rainfall based on an improved Green-Ampt model, however, this method did not consider the impact of slope angle on infiltration.

This paper aims to develop an approach to simulate the water infiltration behavior in twolayer slopes during unsteady rainfall. The rest of this paper is organized as follows:

Section 2 introduces the proposed model. Section 3 are three numerical cases. Section 4 is the discussions. The conclusions are drawn in the end.

\section{Model}

\subsection{Infiltration rate of water in soil slopes}

The infiltration rate of water in soil slopes depends on rainfall intensity and soil infiltration capacity (soil infiltration capacity is determined by Darcy's law (Hillel 1980)). The slope infiltration rate determined by the rainfall intensity can be expressed as:

$$
i_{1}=q_{\text {rain }} \cos \alpha
$$

where, $\alpha$ represents the slope angle (Fig. 1). The cumulative infiltration volume $I$ can be expressed as:

$$
I=z_{f} \Delta \theta
$$

where, $z_{f}$ represents the wetting front depth (the wetting front refers to the interface between the saturated zone and the natural zone as shown in Fig. 2); $\Delta \theta$ represents the difference of the saturated moisture content $\left(\theta_{\text {sat }}\right)$ and the natural moisture content $\left(\theta_{i}\right)$ of soil. According to Eqs.(1) 
and (2), the following relationship is established:

$$
\frac{d I}{d t}=i_{1} \Leftrightarrow \frac{d z_{f}}{d t}=\frac{q_{\text {rain }} \cos \alpha}{\Delta \theta}
$$

according to Eq.(3), the relationship between the wetting front depth and time $(t)$ can be obtained as:

$$
z_{f}=i_{1} t / \Delta \theta
$$

The infiltration rate determined by soil infiltration capacity can be expressed as (i.e., Darcy's law):

$$
i_{2}=k_{s}\left(\frac{z_{f} \cos \alpha+h_{f}}{z_{f}}\right)
$$

where, $k_{s}$ represents the saturated permeability coefficient of soil; $h_{f}$ represents the matrix suction head. According to Eq.(5), the relationship between the wetting front depth and time can be obtained as:

$$
\frac{d z_{f}}{d t}=\frac{i_{2}}{\Delta \theta}
$$

The infiltration rate of water in soils should be the minimum value between $i_{1}$ and $i_{2}$, ie.,

$$
i=\min \left\{i_{1}, i_{2}\right\}
$$

It should be noted that the above derivations all assume that there would be no ponding on the soil surface (Wu et al. 2018). 


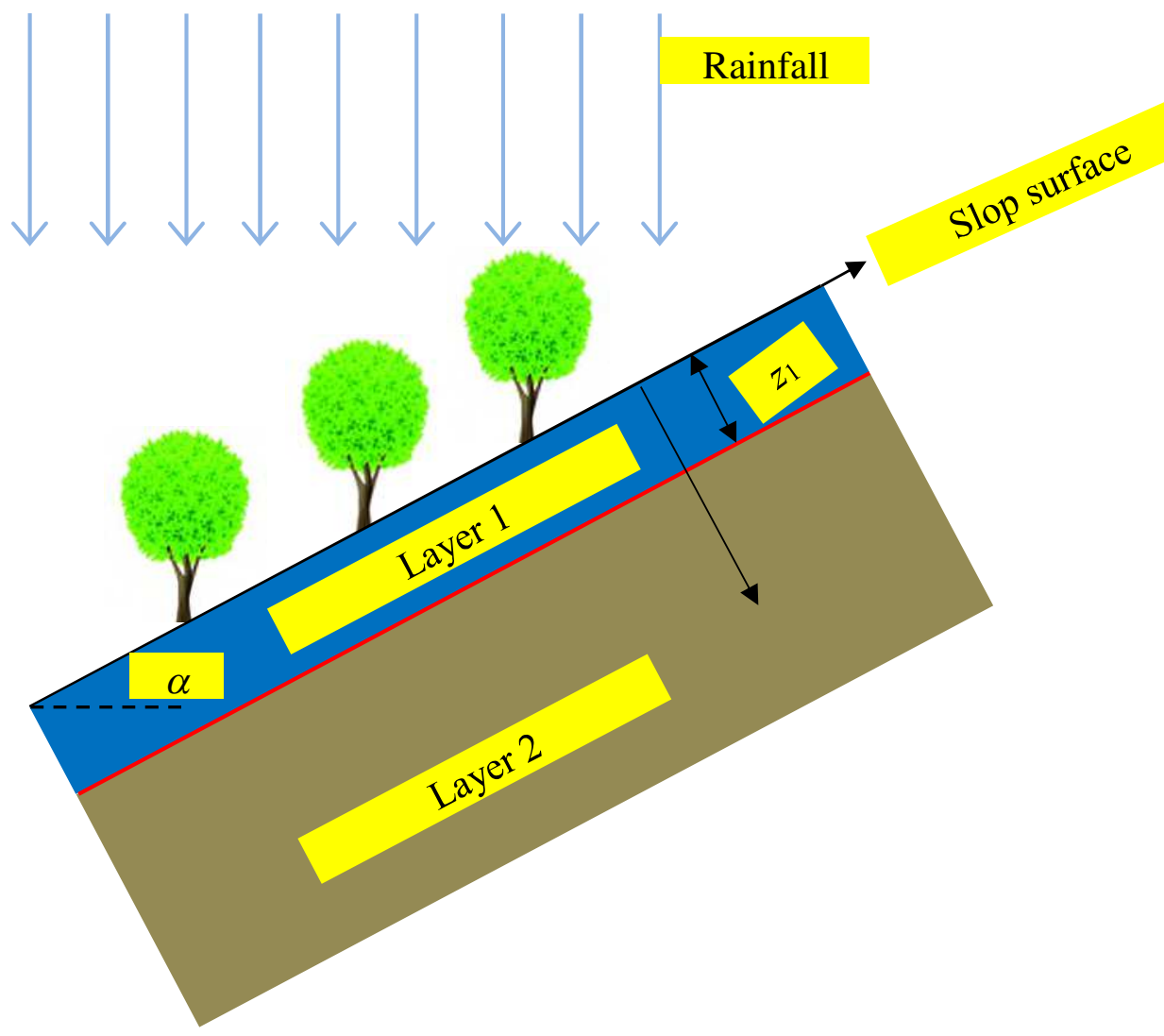

114 Fig. 1 Infiltration in a soil slope during rainfall

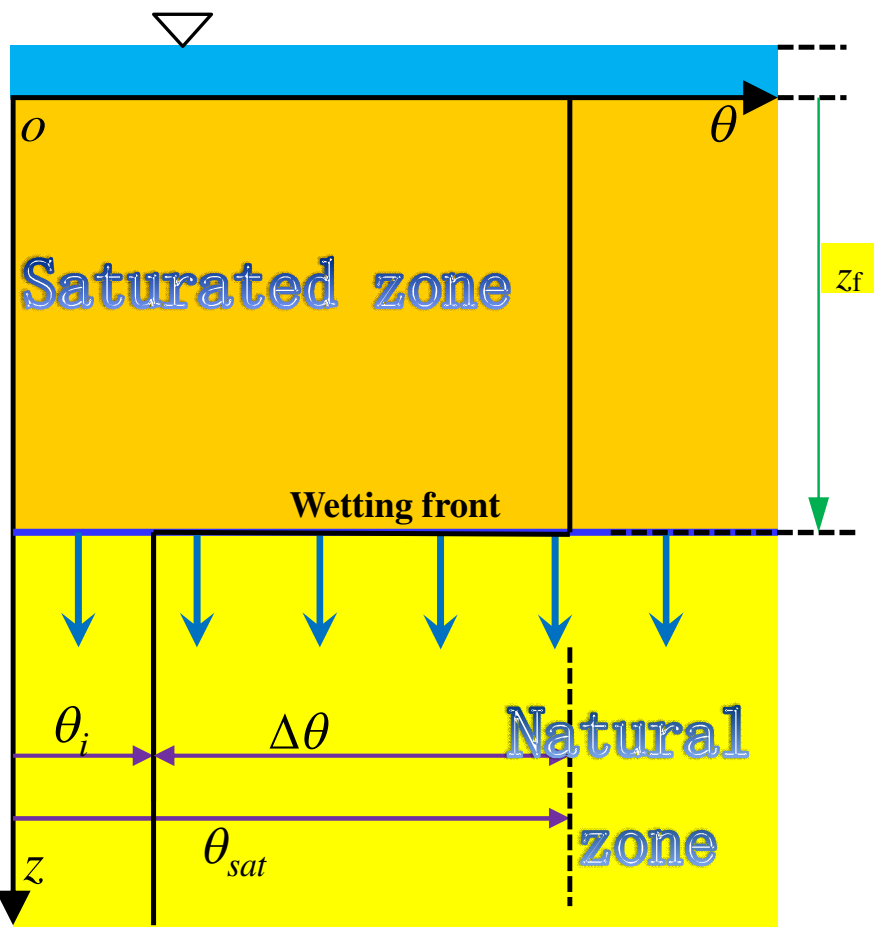

Fig.2 Infiltration behavior of water in the soil 


\subsection{Simulation of water infiltration in two-layer soil slopes}

Let me rewrite Eqs.(4) and (6) into a discretize form $(t=\{0, \Delta t, 2 \Delta t, \mathrm{~K}, i \Delta t, \mathrm{~K}\})$ :

$$
\begin{aligned}
& z_{f, i}=z_{f, i-1}+i_{1} \Delta t / \Delta \theta_{1} \\
& z_{f, i}=z_{f, i-1}+\frac{i_{2}}{\Delta \theta_{1}} \Delta t
\end{aligned}
$$

where, $z_{f, i}$ represents the wetting front depth corresponding to time $i \Delta t\left(z_{f, 0}=0\right)$. To facilitate the distinction, record the saturated permeability coefficient of the layer 1 (Fig. 1) of soil as $k_{s 1}$, and the suction head is denoted as $h_{f 1}$, and the difference of moisture content is $\Delta \theta_{1}$. According to Eqs.(8) and (9), the wetting front depth vs. time in the layer 1 of soil can be obtained. After water penetrating into the layer 2 of soil $\left(z_{f}>z_{1}, z_{1}\right.$ represents the depth of layer 1$)$, the infiltration rate determined by the soil infiltration capacity can be expressed as:

$$
i_{2}=\frac{z_{f} \cos \alpha+h_{f 2}}{\frac{z_{1}}{k_{s 1}}+\frac{z_{f}-z_{1}}{k_{s 2}}}, z_{f}>z_{1}
$$

where, $k_{s 2}$ represents the saturated permeability coefficient of layer 2 , while $h_{f 2}$ represents the matrix suction head of layer 2. The derivation of Eq.(10) can be found in the Appendix. Then the wetting front depth can be expressed as follows:

$$
z_{f, i}=z_{f, i-1}+i_{1} \Delta t / \Delta \theta_{2}
$$

$$
z_{f, i}=z_{f, i-1}+\frac{i_{2}}{\Delta \theta_{2}} \Delta t
$$

where, $\Delta \theta_{2}$ represents the difference of saturated moisture content and natural moisture content of layer 2 .

The flow chart of simulating infiltration of water in the two-layer soil can be seen in Fig.

3. The core of the proposed model is to use difference calculation instead of differential 
two-layer soil slopes during unsteady rainfall.

Combined with the limit equilibrium method, the slope safety factor $(F \mathrm{~s})$ can be expressed as (the wetting front is slip surface) (Zhu et al. 2020):

$$
F_{s}=\frac{c+\left(\gamma z_{f} \cos ^{2} \alpha-\gamma_{w} z_{f} \cos ^{2} \alpha\right) \tan \varphi}{\gamma z_{f} \cos \alpha \sin \alpha}
$$

where, $\gamma$ and $\gamma_{\mathrm{w}}$ represent the unit weight of soil and water, $c$ and $\varphi$ represent cohesion and internal friction angle. The numerator term of Eq.(13) is also called anti-sliding force, and the denominator term is called sliding force. By substituting Eqs.(8)-(12) into Eq.(9), the slope safety factor at any time can be obtained.

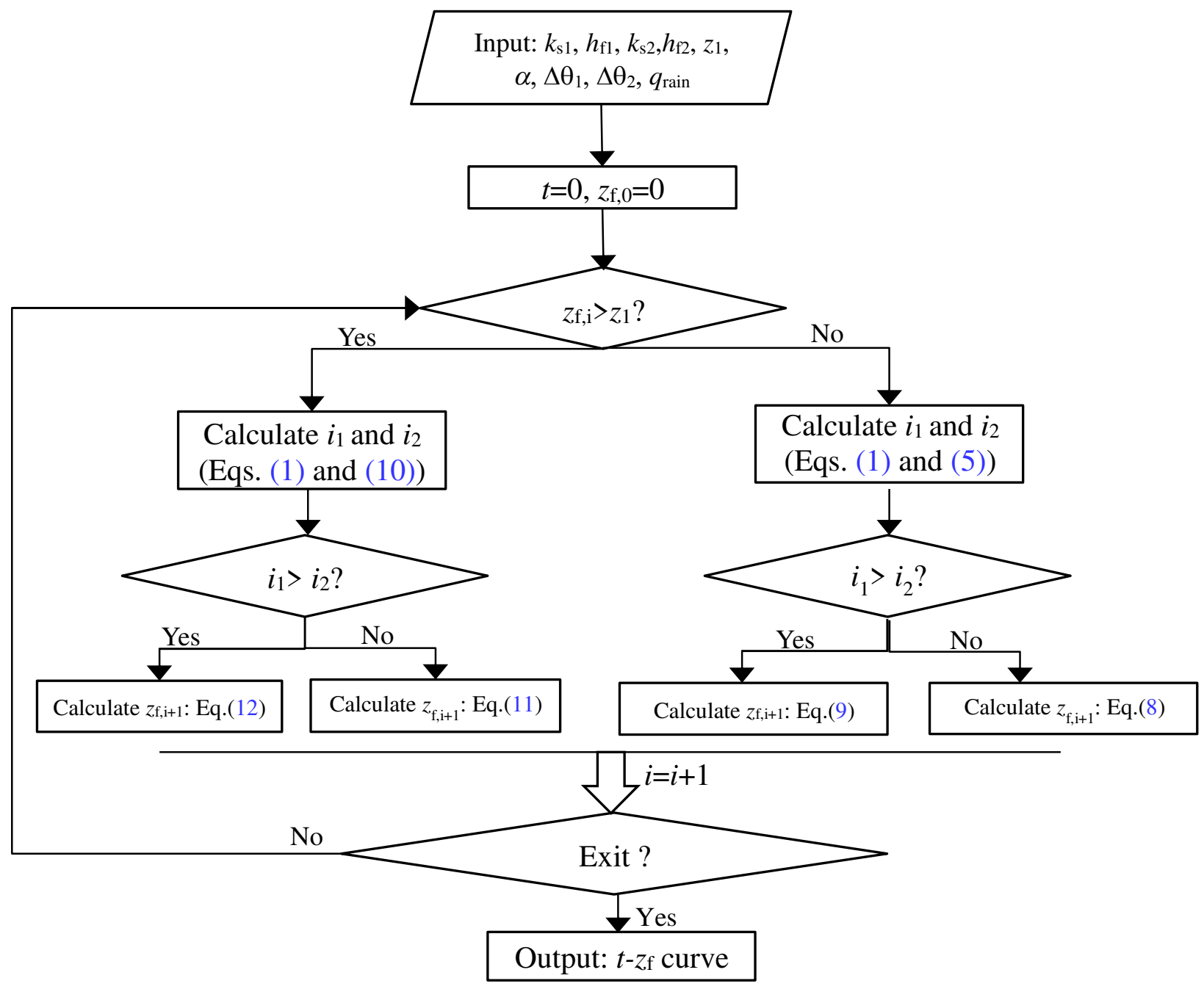


Fig.3 The flow chart of the proposed model

3 Numerical cases

In this section, to facilitate the distinction, record unit weight, cohesion and internal friction angle of the layer 1 as $\gamma_{1}, c_{1}$ and $\varphi_{1}$, respectively, these of layer 2 are denoted as $\gamma_{2}, c_{2}$ and $\varphi_{2}$, respectively. In the following three cases, $\Delta t=5 \mathrm{~min}$. The calculation results in this paper were obtained through MATLAB software (Mathworks 2018a).

\subsection{Case 1: steady rainfall and homogeneous slope}

The calculation parameters are shown in Table 1.

Table 1 Calculation parameters of Case 1

\begin{tabular}{llllllll}
\hline$\Delta \theta_{1}$ & $q_{\text {rain }}(\mathrm{m} / \mathrm{h})$ & $h_{\mathrm{f} 1}(\mathrm{~m})$ & $k_{\mathrm{s} 1}(\mathrm{~m} / \mathrm{h})$ & $\alpha($ deg. $)$ & $c_{1}(\mathrm{kPa})$ & $\varphi_{1}($ deg. $)$ & $\gamma\left(\mathrm{kN} / \mathrm{m}^{3}\right)$ \\
\hline 0.35 & 0.03 & 0.5 & 0.00837 & 30 & 13.5 & 36 & 19.2 \\
\hline
\end{tabular}

Figure 4(a) shows the variation of infiltration rate over time, and we can conclude that the infiltration rate determined by rainfall intensity $\left(q_{\mathrm{rain}} \cos \alpha\right)$ at the beginning of precipitation, while it is determined by infiltration capacity in the later period of precipitation. The wetting front depth vs. time curve is shown in Fig. 4(b). With the decrease of infiltration rate, the forward rate of the wetting front decreases gradually. Figure 4(c) is the safety factor during rainfall. With the increase of rainfall duration, the slope safety factor reduces, indicating that rainfall has a negative influence on the slope stability. 


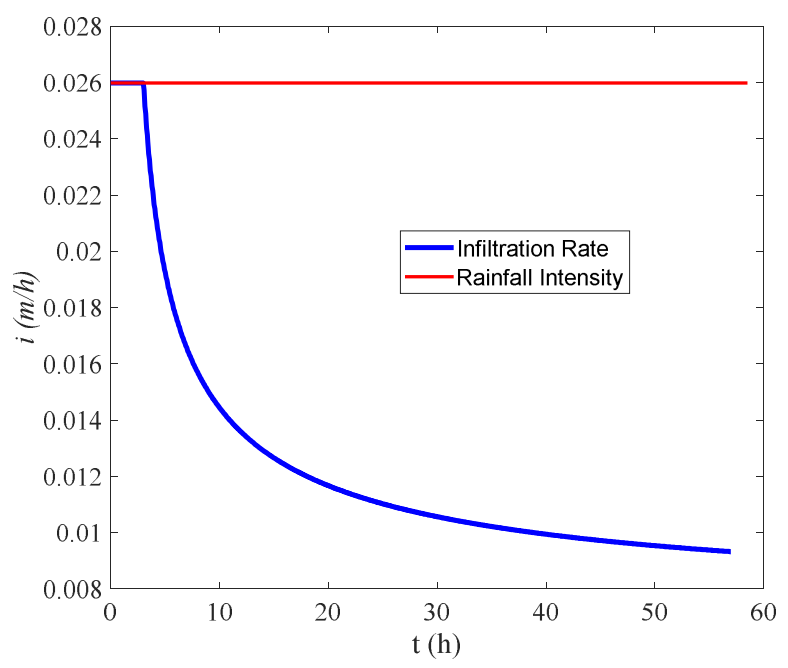

(a)
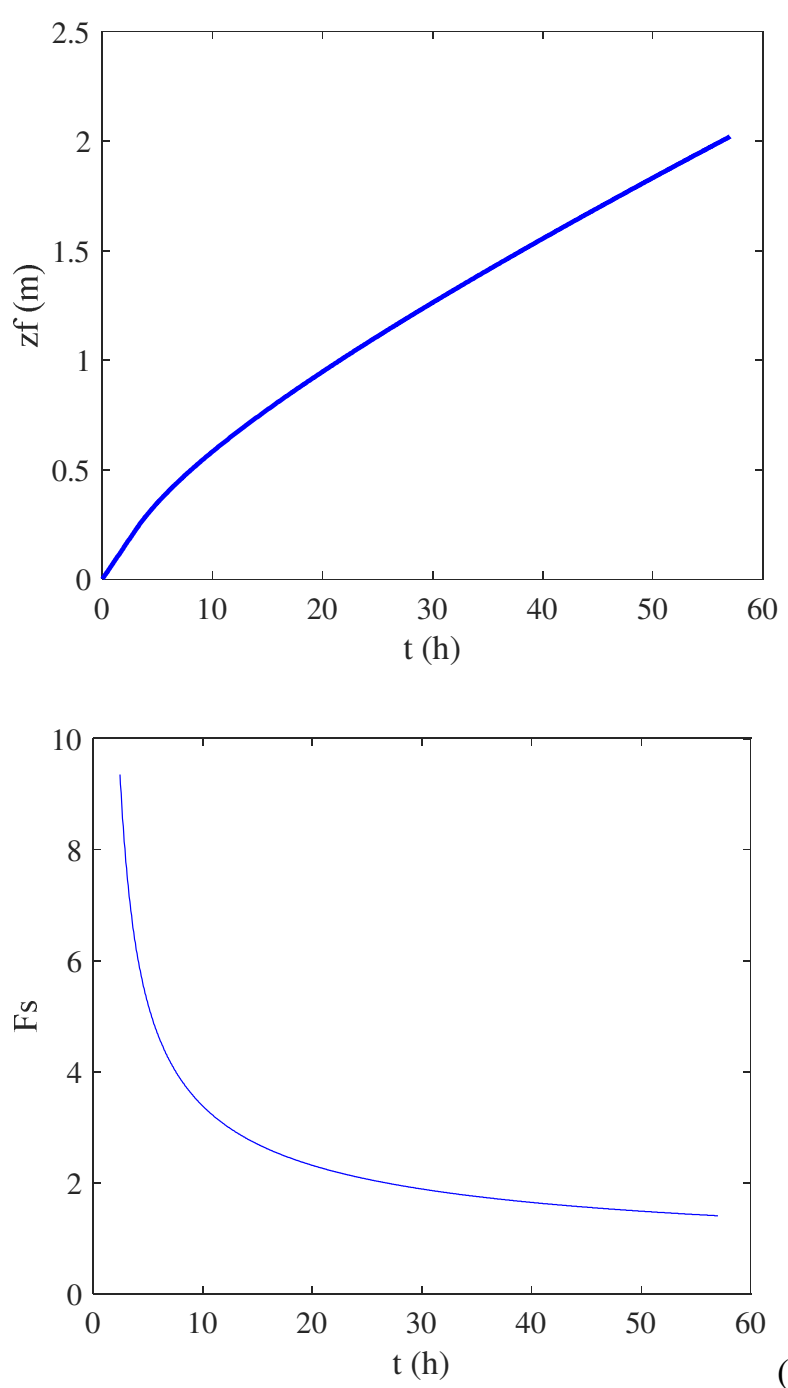

Fig.4 The calculation results of Case 1: (a) rainfall intensity and infiltration rate of water in

soils, (b) the wetting front depth vs. time curve, and (c) the safety factor during rainfall 


$$
\left\{\begin{array}{l}
t=z_{f} \Delta \theta_{1} /\left(q_{\text {rain }} \cos \alpha\right), z_{f}<z_{p} \\
t=t_{p}+A_{1}+A_{2}, z_{f} \geq z_{p}
\end{array}\right.
$$

Fig.5 Res

$$
\left\{\begin{array}{l}
A_{1}=\Delta \theta_{1}\left(z_{f}-q_{\text {rain }} \cos \alpha t_{p}\right) / k_{s 1} \cos \alpha \\
A_{2}=\left(\Delta \theta_{1}\left(-h_{f 1}\right) \ln \left(h_{f 1}-z_{f} \cos \alpha / h_{f 1}-q_{\text {rain }} \cos ^{2} \alpha t_{p}\right)\right) / k_{s 1} \cos ^{2} \alpha
\end{array}\right.
$$

$$
z_{p}=\frac{h_{f 1}}{\left(q_{\text {rain }} / k_{s 1}-1\right) \cos \alpha}
$$

$$
t_{p}=\frac{\Delta \theta_{1} z_{p}}{q_{\text {rain }} \cos \alpha}
$$

Figure 5 compares the results of Eq. (14) with that of the proposed model. As shown in Fig. 5, the results of the proposed model are almostly consistent with that of Eq. (14), which rifies the reasonability and practicability of the proposed method.

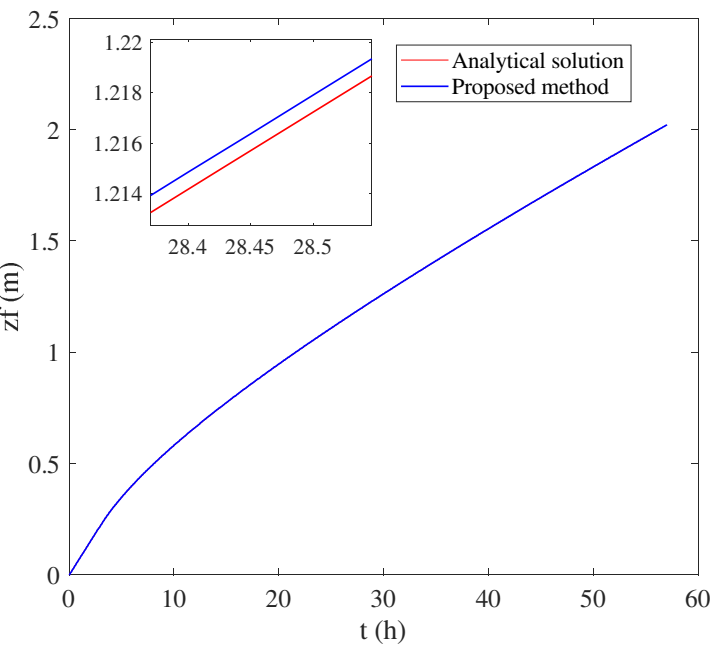

Fig.5 Results of the proposed model and Eq. (14)

\subsection{Case 2: unsteady rainfall and homogeneous slope}

The calculation parameters are shown in Table 2.

\begin{tabular}{lllllll}
\hline$\Delta \theta_{1}$ & $h_{\mathrm{f} 1}(\mathrm{~m})$ & $k_{\mathrm{s} 1}(\mathrm{~m} / \mathrm{h})$ & $\alpha($ deg. $)$ & $c_{1}(\mathrm{kPa})$ & $\varphi_{1}($ deg. $)$ & $\gamma_{1}\left(\mathrm{kN} / \mathrm{m}^{3}\right)$ \\
\hline 0.35 & 0.5 & 0.00837 & 30 & 13.5 & 36 & 19.2 \\
\hline
\end{tabular}



between rainfall intensity and soil infiltration capacity with the variation of rainfall intensity.

Figure6(b) shows the variation of wetting front. Due to the variation of rainfall intensity, it can be seen that there are many turning points in the forward curve of wetting front. Compared with

2 is less than that in Case 1, the safety factor of Case 2 is larger.

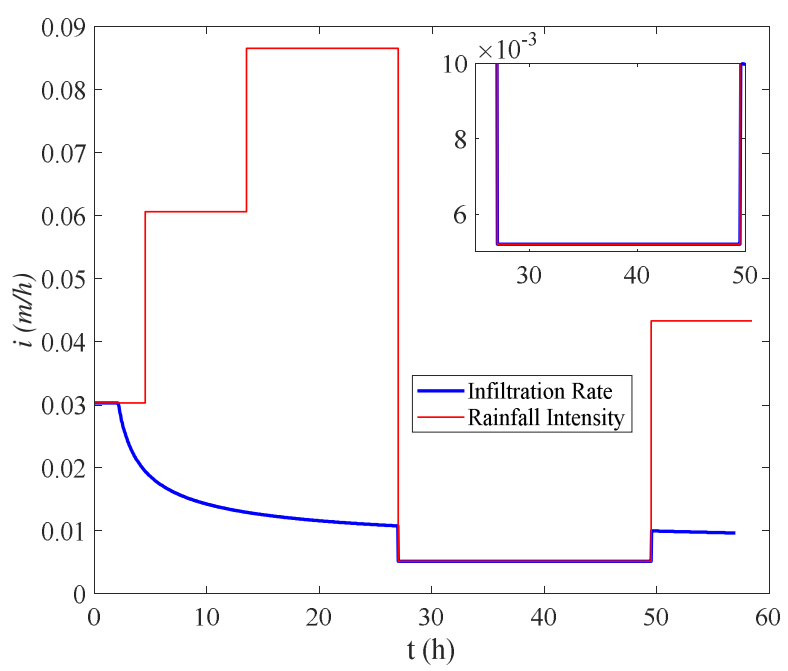

(a)

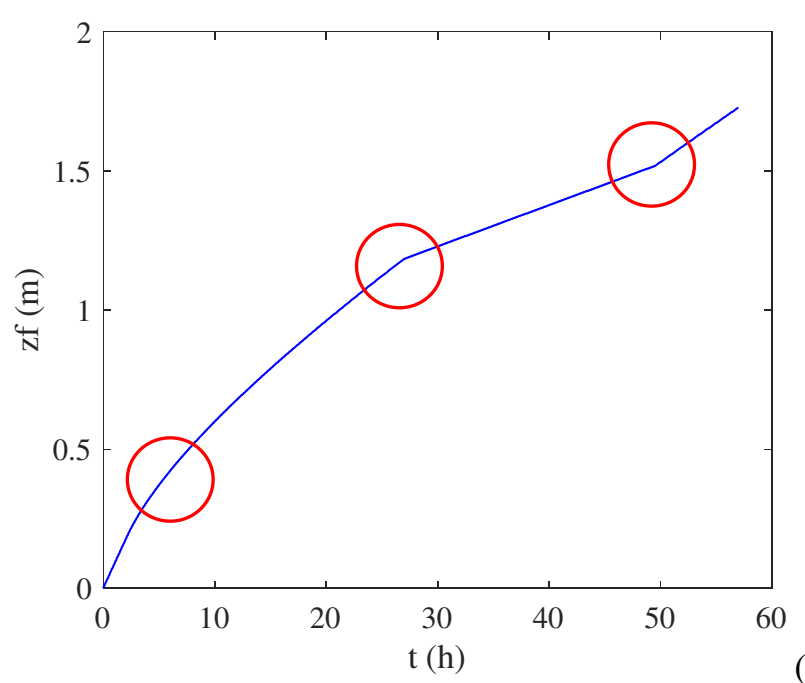

(b) 


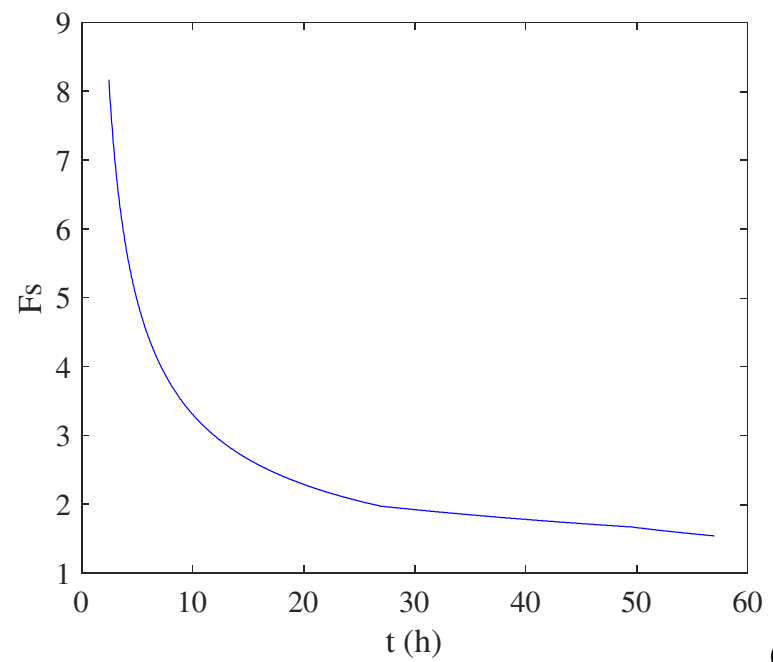

Fig.6 The calculation results of Case 2: (a) rainfall intensity and infiltration rate of water in soil, (b) the wetting front vs. time curve, and (c) the safety factor during rainfall

behavior. Rainfall intensity is unsteady in actual. Howerver, many infiltration models simplify non-uniform rainfall intensity to uniform rainfall intensity, which may result in a nonnegligible difference (e.g., Muntohar and Liao 2010; Zhang et al., 2017; Wu et al. 2018).

\subsection{Case 3: unsteady rainfall rainfall and two-layer slope}

The calculation parameters are shown in Table 3.

Table 3 Calculation parameters of Case 3

\begin{tabular}{cccc}
\hline layer 1 & value & layer2 & value \\
\hline$\Delta \theta_{1}$ & 0.35 & $\Delta \theta_{2}$ & 0.45 \\
$h_{\mathrm{f} 1}(\mathrm{~m})$ & 0.5 & $h_{\mathrm{f} 2}(\mathrm{~m})$ & 0.3 \\
$k_{\mathrm{s} 1}(\mathrm{~m} / \mathrm{h})$ & 0.00837 & $k_{\mathrm{s} 2}(\mathrm{~m} / \mathrm{h})$ & 0.01037 \\
$\alpha(\mathrm{deg})$. & 30 & $\alpha(\mathrm{deg})$. & 30 \\
$c_{1}(\mathrm{kPa})$ & 13.5 & $c_{2}(\mathrm{kPa})$ & 10.5 \\
$\varphi_{1}(\mathrm{deg})$. & 36 & $\varphi_{2}(\mathrm{deg})$. & 30 \\
$\gamma_{1}\left(\mathrm{kN} / \mathrm{m}^{3}\right)$ & 19.2 & $\gamma_{2}\left(\mathrm{kN} / \mathrm{m}^{3}\right)$ & 18 \\
$z_{1}(\mathrm{~m})$ & 1 & & \\
\hline
\end{tabular}

Figure 7(a) is the variation of infiltration rate and rainfall intensity over time. Different 
be converted between rainfall intensity and soil infiltration capacity. About 20h later, when

209 rainfall penetrates into the second layer, the infiltration rate decreases suddenly. Figure7(b)

210 shows the variation of wetting front, compared with that in Case 2, wetting front depth is further

211 reduced. Figure 7(c) is the variation of the slope safety factor during rainfall. Due to the

212 differences in weight, cohesion, and internal friction angle between two soil layers, the safety

213 factor decreases suddenly when water penetrates into the second layer.

214

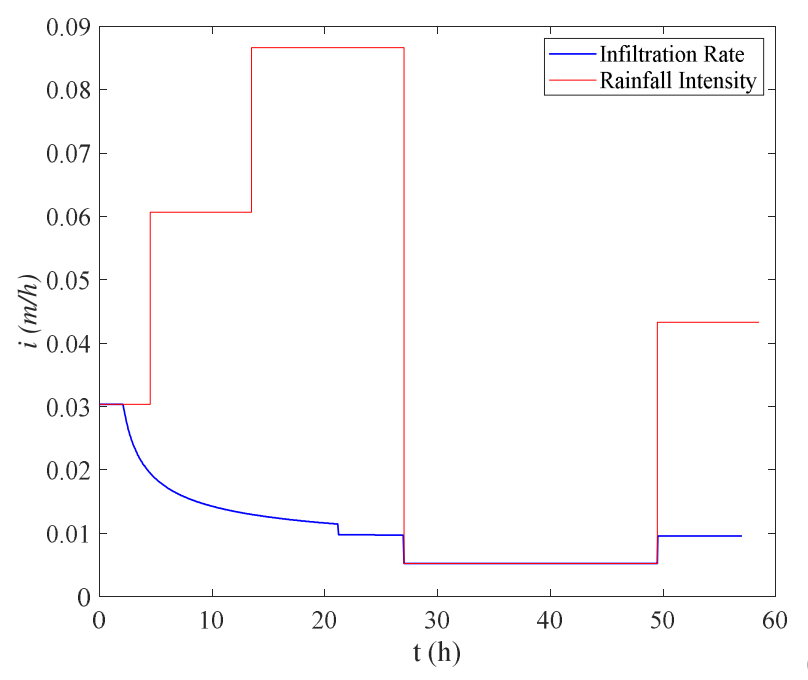

(a)

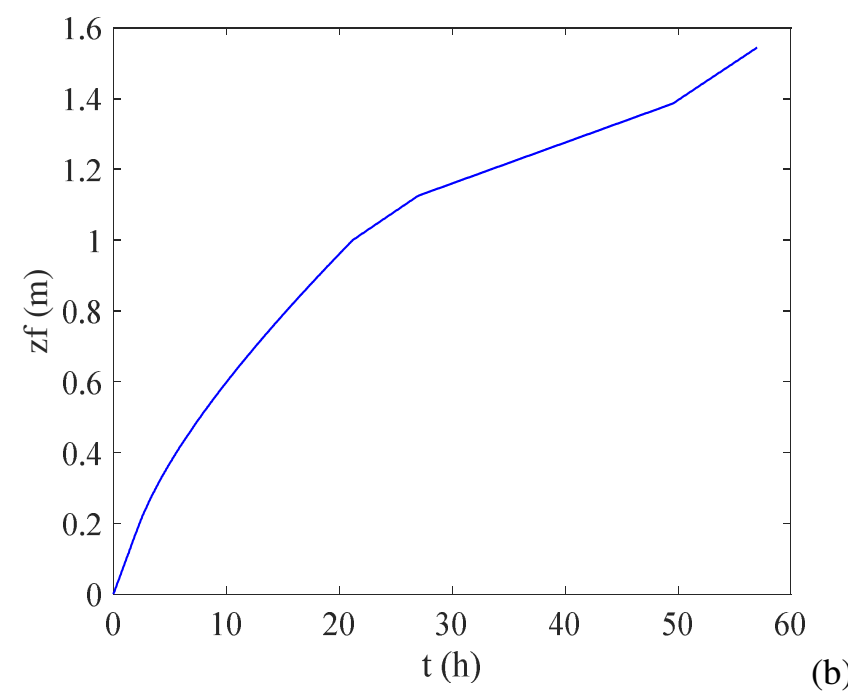




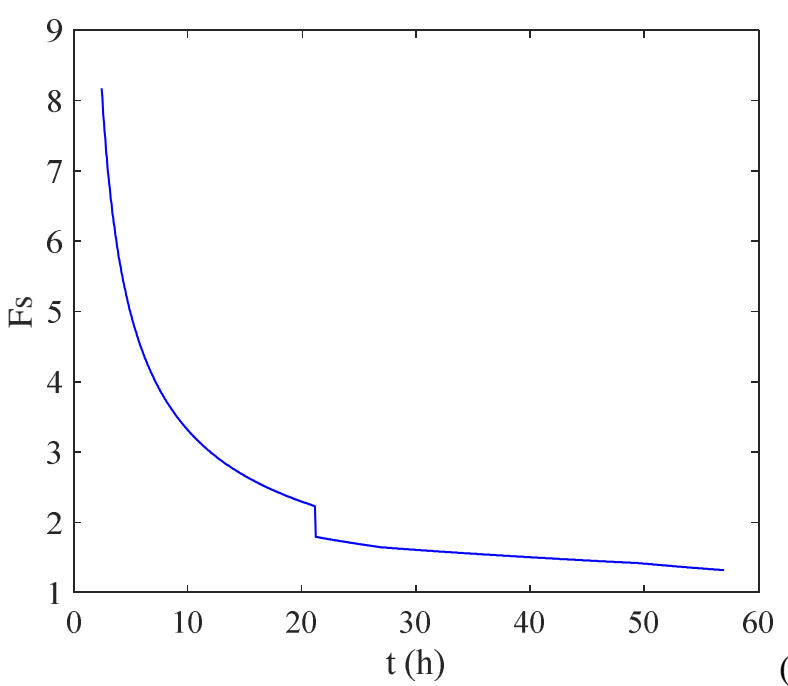

Fig.7 The calculation results of Case 3: (a) rainfall intensity and infiltration rate of water in soil, (b) the wetting front depth vs. time curve, and (c) the safety factor during rainfall mechanical parameters between two layers of soil have a great influence on the infiltration behavior of water.

\section{Discussions}

\section{a) Failure probability analysis of slopes based on the proposed model}

The proposed model can also be used to solve the infiltration problem of multilayer soils (see Appendix) and combined with the probability analysis method to perform the failure probability analysis of the slope (Johari and Fooladi 2020).

By treating the saturated permeability coefficient as a spatial random variable (also known as a random field), the uncertainty analysis in the infiltration process can be performed. The random field of saturation coefficient can be generated by Cholesky decomposition method (Haldar and Sivakumar 2008; Kasama and Whittle 2011). Remember that the number of random fields generated is $N$, where the safety factor is less than 1 and the number is $N_{1}$, then the failure probability of the slope is defined as: 


$$
P_{f}=\frac{N_{1}}{N} \times 100 \%
$$

Figure 8 is a random field of 10,000 samples generated when the mean value of the permeability coefficient is $0.01 \mathrm{~m} / \mathrm{h}$, the coefficient of variation is 0.3 , and the autocorrelation distance is $0.2 \mathrm{~m}$. Since the saturated permeability coefficient is a function of depth, it is necessary to use an infiltration model suitable for multi-layered soil (e.g., proposed model) to obtain the failure probability of the slope.

239

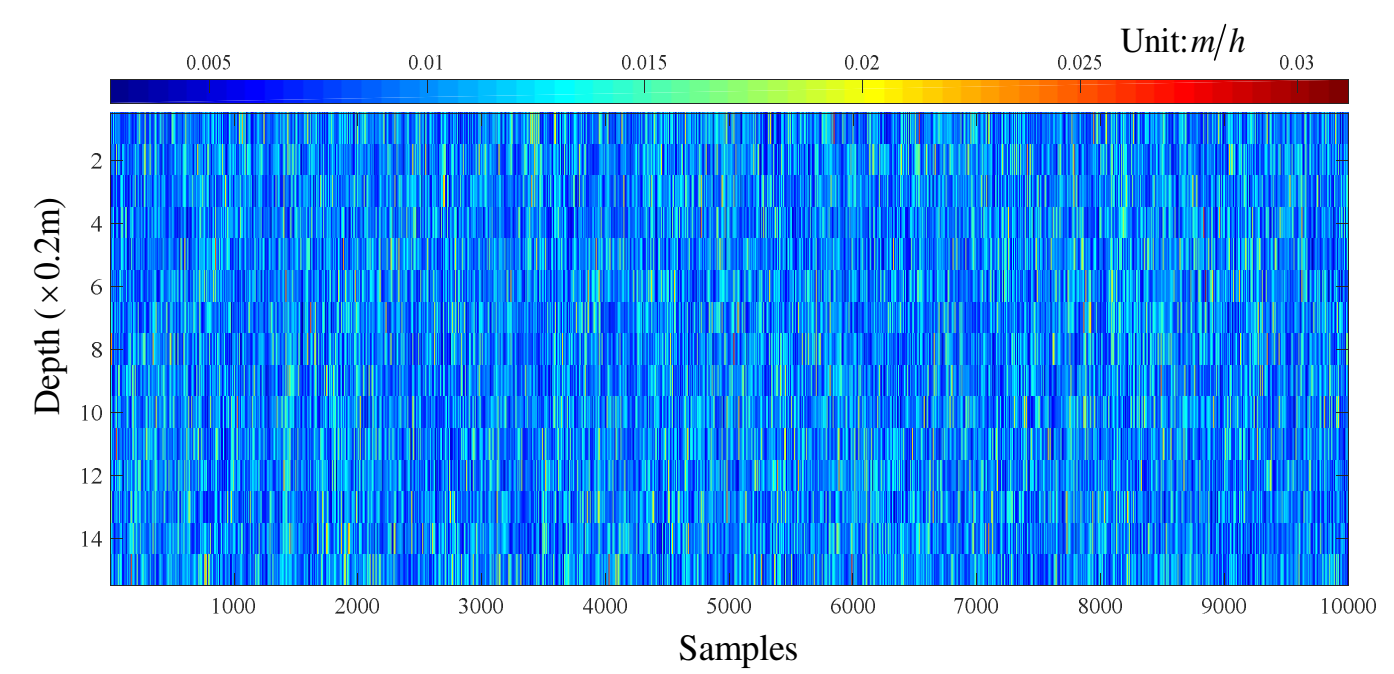

Fig.8 Samples of saturated permeability coefficient

Assume that the soil cohesion is $10 \mathrm{kPa}$ and the internal friction angle is 25 degrees. It should be noted that cohesion and internal friction angle are not regarded as spatial random variables in this paper for simplification. In addition, when the cohesion and internal friction angle are constant, the minimum safety factor of the slope can be obtained only by taking the minimum value of the safety factor at the wetting front and the bedrock surface. According to Fig. 8, the wetting front vs. time curve (Fig. (9a)) and the safety factor vs. time curve (Fig.(9b)) under 10,000 samples were obtained. The failure probability vs. time curve is shown in Fig. 10. The results show that in the first 40 hours, the slope has almost no possibility of instability, and 
(a)

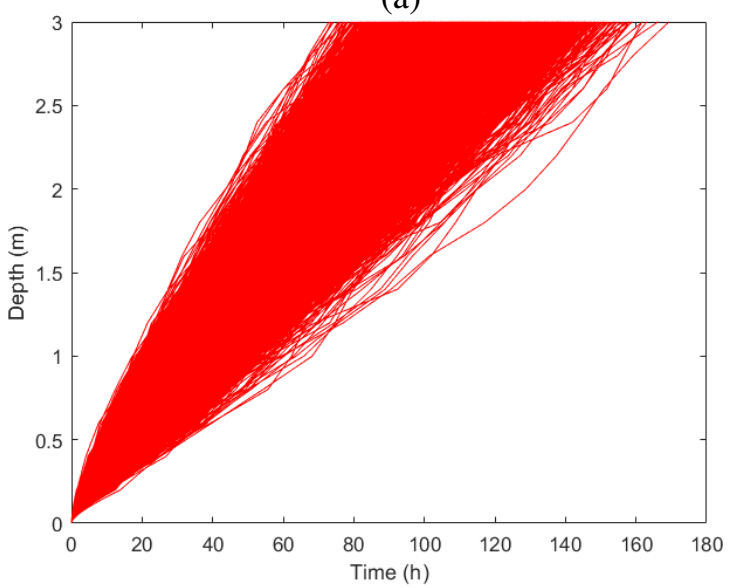

(b)

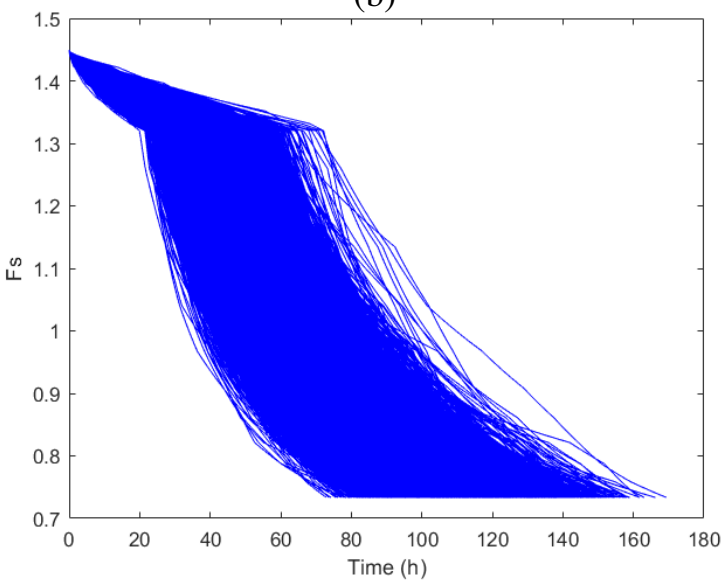

Fig.9 (a) Wetting front depth-time curve and (b) safety factor-time curve

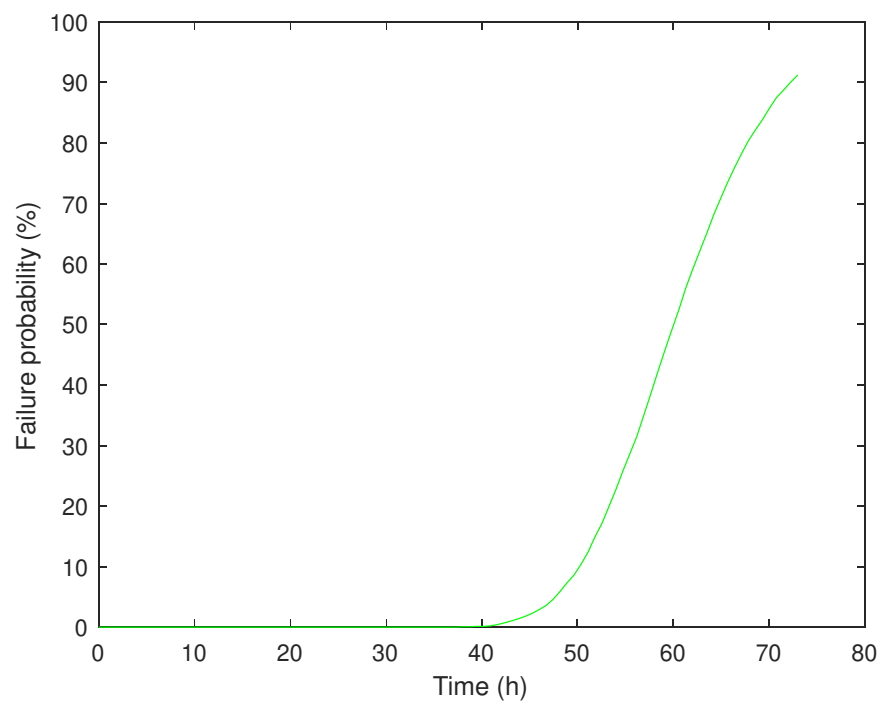

Fig. 10 Slope failure probability during rainfall

Although Dou et al. (2015) has developed a stability uncertainty method for shallow slopes, proposed model to perform uncertain analysis of shallow slopes has the advantages of convenience and speed.

\section{b) Limitations of the proposed model}

Since the moisture in soils is redistributed after rainfall stops, the proposed model cannot be applied to simulate the infiltration of water in soils under the condition of intermittent rainfall. 
Besides, the proposed method did not take into account the unsaturated infiltration characteristics of soils. In future works, the proposed model can also be combined with advanced probability analysis methods to calculate the failure probability of slopes. When performing slope failure probability analysis, the uncertainty of saturated permeability coefficient and soil strength parameters (cohesion and internal friction angle) should be considered.

\section{Conclusions}

The conclusions are drawn as follows:

(1) A simple model for analyzing the infiltration behavior in two-layer soil slopes during unsteady rainfall was proposed. The results of the proposed model are almostly consistent with that of the existing analytical models under the condition of steady rainfall and homogeneous soil slope.

(2) The actual infiltration rate of water is the minimum value of rainfall intensity and the actual infiltration capacity of soils. The differences in unit weight, cohesion, and internal friction angle between two soil layers affect the slope stability.

(3) The proposed model can be combined with probabilistic methods to calculate the failure probability of slopes. Moreover, compared with the existing methods of rainfall and landslide probability analysis, the proposed model highlights convenience and less calculation time.

Future work is to combine the proposed model with advanced probability analysis methods to calculate the failure probability of slopes.

\section{Appendix}


As shown in Fig. 1, after water penetrating into the second layer, the uniform rate of wetting front can be expressed as:

$$
i_{2}=k_{s 1} \frac{H_{0}-H_{1}}{z_{1}}=k_{s 2} \frac{H_{1}-H_{z_{f}}}{z_{f}-z_{1}}
$$

where, $H_{0}$ represents the head height of slope surface, while $H_{1}$ represents the head height of the contact surface of two layers of soil and $H_{\mathrm{zf}}$ represents the head height at wetting front, and there have:

$$
\left\{\begin{array}{l}
H_{0}=0 \\
H_{z_{f}}=z_{f} \cos \alpha+h_{f 2}
\end{array}\right.
$$

Substituting Eq.(16) into Eq.(15) leads to:

$$
H_{1}=-\frac{k_{s 2} \frac{z_{f} \cos \alpha+h_{f 2}}{z_{f}-z_{1}}}{\frac{k_{s 1}}{z_{1}}+\frac{k_{s 2}}{z_{f}-z_{1}}}
$$

We can obtain Eq.(10) by substituting Eq.(17) into Eq.(15).

In fact, if soil slope more than two layers, in the $n$th layer of soil, the infiltration rate determined by soil infiltration capacity can be expressed as:

$$
i_{n}=\frac{z_{f} \cos \alpha+h_{f n}}{\sum_{j=1}^{n-1} \frac{z_{j}-z_{j-1}}{k_{s j}}+\frac{z_{f}-z_{n-1}}{k_{s n}}}
$$

where, $k_{\mathrm{sj}}$ represents the saturated permeability coefficient of the $j$ th layer of soil, and $h_{\mathrm{fn}}$ represents the suction head of the $n$th layer soil and $z_{\mathrm{j}}$ represents the height of the $j$ th layer of soil. 


\section{Acknowledgments}

301

We thank the National Natural Science Foundation of China (no. 41672282) and the National

Key Research and Development Program of China (no. 2018YFC1504702).

\section{Data availability}

All data generated or analyzed during this study are included within the article.

\section{Conflict of interest}

The authors declare that they have no conflict of interest.

\section{References}

Alcantara-Ayala I. (2004). Hazard assessment of rainfall-induced landsliding in mexico. Geomorphology 61(1-2) 19-40.

Almedeij J, Esen II. (2014). Modified Green-Ampt infiltration model for steady rainfall. Journal of Hydrologic Engineering 19(9) 04014011.

Barry DA, Parlange JY, Li L, Jeng DS, Crapper M. (2005). Green-Ampt approximations. Advances in Water Resources 28(10) 1003-1009.

Chen L, Young MH. (2006). Green-ampt infiltration model for sloping surfaces. Water Resources Research 42(7) 887 - 896.

Cho SE. (2009). Infiltration analysis to evaluate the surficial stability of two-layered slopes considering rainfall characteristics. Engineering Geology 105(1-2) 32-43.

Collins BD, Znidarcic D. (2004). Stability analyses of rainfall induced landslides. Journal of Geotechnical and Geoenvironmental Engineering 130 (4) 362-372.

Dai FC, Lee CF, Ngai YY. (2002). Landslide risk assessment and management: an overview. 
Deng P, Zhu JT. (2016). Analysis of effective Green-Ampt hydraulic parameters for vertically layered soils. Journal of Hydrology 538 705-712.

De Luca DL, Cepeda JM. (2016). Procedure to obtain analytical solutions of one-dimensional Richards' equation for infiltration in two-layered soils. Journal of Hydrologic Engineering 21(7) 04016018.

Dou HQ, Han TC, Gong XN, Zhang J. (2014). Probabilistic slope stability analysis considering the variability of hydraulic conductivity under rainfall infiltration-redistribution conditions. Engineering Geology 183 1-13.

Dou HQ, Han TC, Gong XN, Qiu Z, Li Z. (2015). Effects of the spatial variability of permeability on rainfall-induced landslides. Engineering Geology 192 92-100.

Fernández-Pato J, Gracia JL, García-Navarro P. (2018). A fractional-order infiltration model to improve the simulation of rainfall/runoff in combination with a $2 \mathrm{D}$ shallow water model. Journal of Hydroinformatics 20(4) 898-916.

Green WH, Ampt GA. (1911). Studies on soil phyics. The Journal of Agricultural Science 4(1) $1-24$.

Haldar S, Sivakumar BGL. (2008). Effect of soil spatial variability on the response of laterally loaded pile in undrained clay. Computers and Geotechnics 35(4) 537-547.

Hillel D. (1980). Fundamentals of soil physics. Academic Press, New York, NY.

Johari A, Fooladi H. (2020). Comparative study of stochastic slope stability analysis based on conditional and unconditional random field. Computers and Geotechnics 125103707.

Kasama K, Whittle AJ. (2011). Bearing capacity of spatially random cohesive soil using 
numerical limit analysis. Journal of Geotechnical and Geoenvironmental Engineering, ASCE 137(11) 989-996.

Liu EL, Yu HS, Deng G, Zhang JH, He SM. (2014). Numerical analysis of seepage-deformation in unsaturated soils. Acta Geotechnica 9 1045-1058.

Liu GX, Craig JR, Soulis ED. (2011). Applicability of the Green-Ampt infiltration model with shallow boundary conditions. Journal of Hydrologic Engineering16(3) 266-273.

Mao LL, Li Y, Hao W, Zhou X, Xu C, Lei T. (2016). A new method to estimate soil water infiltration based on a modified Green-Ampt model. Soil and Tillage Research 161 31-37.

Mathworks. (2018a). MATLAB Version 9.4.0. The Mathworks, Inc. Natick, Massachusetts.

Mein RG, Larson CL. (1973). Modeling infiltration during a steady rain. Water Resources Research 9(2) 384-394.

Muntohar AS, Liao HJ. (2010). Rainfall infiltration: infinite slope model for landslides triggering by rainstorm. Natural Hazards 54 967-984.

Voller VR. (2011). On a fractional derivative form of the Green-Ampt infiltration model. Advances in Water Resources 34(2) 257-262.

Wang DJ, Tang HM, Zhang YH, Li CD, Huang L. (2017). An improved approach for evaluating the time-dependent stability of colluvial landslides during intense rainfall. Environmental Earth Sciences 76321.

Wu LZ, Zhang LM, Zhou Y, Xu Q, Yu B, Liu GG, Bai LY. (2018). Theoretical analysis and model test for rainfall-induced shallow landslides in the red-bed arearegion of Sichuan. Bull Eng Geol Environ 77 1343-1353.

Wu LZ, Huang JS, Fan W, Li X. (2020). Hydro-mechanical coupling in unsaturated soils 
covering a non-deformable structure. Computers and Geotechnics 117103287.

Tang YM, Xue Q, Li ZG, Feng W. (2015). Three modes of rainfall infiltration inducing loess landslide. Natural Hazards 79 137-150.

Tsaparas I, Rahardjo H, Toll D, Leong E. (2002). Controlling parameters for rainfall-induced landslides. Computers and Geotechnics 29(1) 1-27.

Zhang S, Xu Q, Zhang Q. (2017). Failure characteristics of gently inclined shallow landslides in Nanjiang, southwest of China. Engineering Geology 217 1-11.

Zhan TLT, Jia GW, Chen YM, Fredlund DG, Li H. (2012). An analytical solution for rainfall infiltration into an unsaturated infinite slope and its application to slope stability analysis. International Journal for Numerical and Analytical Methods in Geomechanics 37(12) 1737-1760.

Zhang QY, Chen WW, Zhang YM. (2019). Modification and evaluation of Green-Ampt model: Dynamic capillary pressure and broken-line wetting profile. Journal of Hydrology 575 $1123-1132$.

Zhu SR, Wu LZ, Peng JB. (2020). An improved Chebyshev semi-iterative method for simulating rainfall infiltration in unsaturated soils and its application to shallow landslides. Journal of Hydrology 125157. 
Table 1 Calculation parameters of Case 1

Table 2 Calculation parameters of Case 2

Table 3 Calculation parameters of Case 3

Fig. 1 Infiltration in a soil slope during rainfall

Fig.2 Infiltration behavior of water in the soil

Fig.3 The flow chart of the proposed model

Fig.4 The calculation results of Case 1: (a) rainfall intensity and infiltration rate of water in

soils, (b) the wetting front vs. time curve, and (c) the safety factor during rainfall

Fig.5 Results of the proposed model and Eq. (14)

Fig.6 The calculation results of Case 2: (a) rainfall intensity and infiltration rate of water in soil,

(b) the wetting front depth vs. time curve, and (c) the safety factor during rainfall

Fig.7 The calculation results of Case 3: (a) rainfall intensity and infiltration rate of water in soil,

(b) the wetting front depth vs. time curve, and (c) the safety factor during rainfall

Fig.8 Samples of saturated permeability coefficient

Fig.9 (a) Wetting front depth-time curve and (b) safety factor-time curve

Fig. 10 Slope failure probability during rainfall 